\title{
Derecho indígena comparado: el derecho indígena desde sus propios parámetros
}

\section{Indigenous law compared: Indigenous law analyzed from its own parameters}

\author{
Elisa Cruz Rueda* \\ María del Pilar Elizondo Zenteno** \\ doi.org/10.29043/liminar.v20i1.887
}

Resumen: El interés de este artículo es mostrar la importancia del estudio del derecho indígena desde sus propios parámetros. Se presentan los resultados de la revisión de estudios desde la Antropología y el Derecho sobre los sistemas normativos indígenas. A partir de esto se concluye que para hacer efectivo el pluralismo jurídico y el reconocimiento de la pluriculturalidad de México de acuerdo con la Constitución Política de los Estados Unidos Mexicanos, art. $2^{\circ}$, es necesario el estudio del derecho indígena desde sus propios parámetros; de lo contrario, cualquier diálogo que pretenda ser intercultural en realidad seguiría reproduciendo esquemas de imposición de la cultura hegemónica sobre el resto de los pueblos que conforman la nación mexicana.

Palabras clave: otredad, diversidad cultural, peritaje antropológico, derechos humanos, sistemas normativos.

Abstract: The objective of this article is to underscore the importance of studying indigenous law based on its own parameters. We discuss the results of a scholarly literature review regarding indigenous normative systems within the fields of anthropology and law. We conclude that to achieve real legal pluralism and recognize Mexico's pluriculturality in keeping with Article Two of its Constitution, it is necessary to study indigenous law based on its own parameters. Otherwise, any dialogue that claims to be intercultural would continue to reproduce the imposition of the hegemonic culture on the rest of the peoples that make up the Mexican nation.

Key words: otherness, cultural diversity, anthropological expertise, human rights, normative systems.

Recibido: 31 de octubre de 2020 Aprobación: 4 de junio de 2021 Publicación: 23 de septiembre de 2021
* Escuela de Gestión y Autodesarrollo Indígena de la Universidad Autónoma de Chiapas, Tuxtla Gutiérrez, México elisacruzrueda@hotmail.com (iD) 0000-0002-6339-1518

** Doctorado de Estudios Regionales, Universidad Autónoma de Chiapas, Tuxtla Gutiérrez, México mpzenteno1@hotmail.com (iD) 0000-0003-2749-2095 


\section{Introducción $^{1}$}

$\mathrm{L}$ a libre determinación como expresión de la autonomía de los pueblos indígenas pasa por reconocer el pluralismo jurídico, entendido como la existencia y confluencia de parámetros culturales diversos desde los cuales se puede observar un mismo objeto, pero con criterios culturalmente disímbolos y en ocasiones hasta antagónicos, circunstancia revelada al momento de hacer justicia, por ejemplo. Pese a esto, los indígenas y sus pueblos han aceptado los marcos de pensamiento estatales para nombrar y dar contenido a sus sistemas normativos, mientras que el sistema hegemónico estatal no cambia de fondo. Frente a este hecho, ¿puede decirse que existe un efectivo pluralismo jurídico?

En este sentido, se realizó una revisión bibliográfica para determinar hasta dónde se revela en la producción académica la característica principal del derecho indígena, tomando distancia del derecho positivo. Se reconoce que esto es una empresa nada fácil si se toma en cuenta que el derecho es un concepto que surge en el seno de los Estados nacionales concebidos desde una idea monolítica y homogenizante de la población y el territorio. A esta dificultad se agrega que las bases del pensamiento estatista solo aceptan realidades constatables por los sentidos y están encuadradas en la doctrina del derecho que dicta lo que deben ser las normas jurídicas, sus requisitos y características, lo que deja fuera, y por mucho, el pensamiento indígena, que toma en cuenta otros planos que no se pueden verificar a través de los sentidos, ni se pueden condensar o plasmar en normas escritas.

Para lograr este propósito, se desarrollaron tres apartados. En el primero, "El derecho indígena desde afuera" se abordan los conceptos centrales como interlegalidad y pluralismo jurídico, es decir, cómo se reconoce el derecho indígena en la Constitución Política de los Estados Unidos Mexicanos (CPEUM) por los abogados y jurisconsultos no indígenas. En el segundo "El punto de transición entre lo ajeno y lo propio: la antropología y la antropología jurídica", se expone el enfoque de estas disciplinas en el estudio de otros centros generadores de normas distintos al Estado. En el tercer apartado se aborda el derecho indígena desde sus propios parámetros, y se exponen los parámetros del pensamiento indígena y sus campos; los planos y dimensiones: lo superior, lo material y lo espiritual. Finalmente, en el apartado cuarto se exponen las reflexiones finales.

\section{El derecho indígena desde afuera}

En principio, se parte de que el derecho indígena es una denominación que se sitúa políticamente frente a la de otros sistemas normativos, está expresamente señalada en la CPEUM y tiene que ver con el contexto político de relación entre el Estado, la sociedad mexicana y los pueblos indígenas en México. Esta designación se puso de manifiesto en el alzamiento zapatista de 1994 y, posteriormente, en el debate de los llamados Acuerdos de San Andrés firmados en 1996. En estas discusiones, el Gobierno federal y el del estado de Chiapas rechazaban que los indígenas tuvieran derecho a tener su propio ordenamiento

\footnotetext{
${ }^{1}$ El presente artículo se trata de un estudio analítico sobre el trabajo etnográfico realizado por otros autores y autoras. Entre estos, nos interesa revisar los enfoques usados para abordar el estudio del derecho indígena. Considerando que la bibliografía es muy extensa, sobre todo la etnográfica, para efectos de este artículo solo tomamos algunos referentes, los que consideramos elementales y suficientes, y esperamos en una obra más amplia cumplir la exigencia de exhaustividad que el tema amerita.
} 
jurídico, y en aras de avanzar en los acuerdos se aceptó, por zapatistas y gobiernos, aplicar la denominación de "sistemas normativos indígenas", y quedó así plasmado en la Constitución mexicana desde 2001.

Por otro lado, desde la academia, y sobre todo desde los jurisconsultos o abogados, se ha llamado derecho indígena al conjunto de normas que los indígenas en sus comunidades y pueblos formulan y aplican, pero siempre bajo el filtro de lo que el derecho mexicano considera normatividad jurídica. Desde otros ámbitos se llama derecho indígena a lo que la CPEUM y las leyes del Estado señalan como sistemas normativos. Por eso es de destacar que la definición de "derecho indígena" se vuelve polisémica y su significado depende de quién lo observe, cómo lo observe y cómo lo defina.

Sin embargo, y pese a todo, se prefiere emplear el término "derecho indígena" al de "sistemas normativos" o al de "derecho propio" por las razones que enmarcaron el alzamiento zapatista y los llamados Diálogos de San Andrés.

El planteamiento tiene su base en el pluralismo jurídico y la interlegalidad, y nuestra autocrítica a un trabajo anterior (Cruz, 2008), ya que la perspectiva de análisis en ese momento era desde el enfoque del derecho positivo mexicano, y excluía el estudio del derecho indígena desde sus propios parámetros, de corto horizonte e insuficiente para incluir la otredad del derecho indígena.

Antes de entrar en materia, es importante explicar qué es el estudio comparado del derecho indígena y cuál es la importancia de este. Así, en primer lugar, lo que se ha dado en llamar derecho indígena comparado presupone la existencia de órdenes jurídicos construidos desde las comunidades y pueblos indígenas, cuyos parámetros se tienen que encontrar o formular intentando tomar distancia del derecho positivo mexicano. El examen comparativo entre lo que postula cada ordenamiento indígena como producto cultural es lo que llamamos derecho indígena comparado, y se lleva a cabo desde sus propios parámetros porque, si bien se elogia y reconoce la amplia producción sobre derecho indígena y sistemas de cargos indígenas desde la antropología - muchas veces no indígena o de autoría no indígena-, en realidad lo que nos interesa es el análisis hecho por pensadores indígenas o no indígenas —sean abogados, antropólogos o legos- que toman distancia de los postulados del derecho positivo. Es importante señalar y reconocer que no es garantía ser abogado o abogada indígena para lograr dar cuenta del pensamiento indígena distanciado del pensamiento positivista y estatista; esto, porque la educación superior, y sobre todo la de las facultades y escuelas de derecho, no es intercultural.

De la revisión que se ha hecho se puede constatar que el derecho indígena se ha estudiado desde los parámetros del pensamiento del derecho mexicano de corte eminentemente estatal, hegemónico, monista y monolítico. ${ }^{2}$ En segundo lugar, y ampliando la respuesta a la pregunta planteada al inicio de la introducción de este trabajo, justamente el derecho indígena como derecho es un concepto político y polisémico que comenzó con el nombre de sistema de cargos, gobierno indígena, usos y costumbres, y que transitó a lo que hoy en día es el derecho consuetudinario, pasando por ser llamado sistema normativo indígena, hasta llegar al denominado derecho propio y derecho indígena, trayecto que nos conduciría a una historia de más de treinta años atrás, pero que no abordaremos aquí por salir de los límites de este artículo.

\footnotetext{
${ }^{2}$ Aunque muchas veces se trata de alejar ese pensamiento, no hay un horizonte o propósito de avanzar más allá de lo que se ha planteado como una exigencia de lo conmensurable, es decir, de que las normas indígenas, para ser jurídicas, tienen que ser comparables y, por tanto, cumplir los requisitos que el derecho estatal o derecho mexicano señala para dichas normas, dejando de lado elementos que no se pueden medir con el mismo "cuenco" o la misma "regla" y que serían los que caracterizarían al derecho indígena y lo distinguirían del derecho positivo mexicano.
} 


\section{Pluralismo jurídico e interlegalidad}

Para desarrollar este punto, se manifiesta la amplia discusión sobre estos dos conceptos (Chenaut y Sierra, 1995; De Sousa y García, 2006; Krotz, 2002; Sierra, 1996; Sierra y Chenaut, 2002; Stavenhagen e Iturralde, 1990). El pluralismo jurídico es contraparte del monismo jurídico, este es de origen estatista y postula la existencia exclusiva del Estado como centro generador de normas jurídicas. En contraposición, el pluralismo jurídico plantea la existencia de varios centros generadores que coexisten en un mismo tiempo y espacio, que son igualmente válidos, pero con distintos parámetros de eficacia. Si se reconoce esto, se puede pensar en las relaciones que se dan entre esas fuentes de normas jurídicas, y se estaría frente al fenómeno de la interlegalidad que postula la existencia de distintos niveles legales y en cada uno la posibilidad de la existencia de varios centros generadores de derecho que se interrelacionan entre sí.

De esta manera, para el derecho mexicano, y concretamente en la CPEUM — párrafo cuarto del artículo $2^{\circ}-$, los sistemas normativos indígenas - que reciben la denominación de "derecho indígena"pertenecen a un nivel legal más que a un campo jurídico autónomo.

Es decir, si bien se reconocen los sistemas normativos indígenas, estos son y existen en tanto que cumplen con ciertos requisitos señalados por el Estado; en otras palabras, existen porque son nombrados por él, en una suerte de asimilacionismo jurídico - los sistemas jurídicos indígenas deben ser semejantes o adoptar características del derecho mexicano para ser validados por él, porque adoptan sus formas y fórmulas argumentativas-.

Esto es así porque la Constitución federal mexicana surge en un contexto histórico de invisibilización de la diversidad y la pluralidad y porque el campo de lo jurídico se desarrolla a partir de las reglas del Estado. Es decir, para que las normas sean consideradas jurídicas deben emanar del centro generador legitimado para eso y con procedimientos reconocidos en el marco del Estado nacional, a saber, deben estar promulgadas por el poder legislativo. O bien, en última instancia, las normas que no sean generadas por el Estado solo serán jurídicas si cumplen los requisitos que ese centro generador establezca.

Por lo anterior, la interlegalidad se da cuando se reconoce la existencia de centros generadores de derecho que son iguales en valía a los del Estado, pero, como se ha observado en la lectura del artículo $2^{\circ}$ de la CPEUM, no hay tal igualdad o relación de legalidades mutuamente reconocidas, ya que el Estado solo reconoce aquellas que son semejantes y se ajustan a sus propias reglas de validación, por lo que la relación no es de interlegalidad —-mutua influencia y reconocimiento en valía—, más bien es de subordinación.

\section{El derecho indígena explicado por los abogados y jurisconsultos no indígenas}

Desde la experiencia profesional y docente, se puede constatar que las facultades y escuelas de derecho cumplen su función de formadoras de abogados y abogadas que se encuadran en los parámetros del derecho positivo vigente. Por lo tanto, cuando esos abogados y abogadas, en el ejercicio de su profesión, se insertan en contextos de diversidad en todas sus formas y sobre todo de indígenas y sus pueblos, mucha de la cosmovisión indígena relacionada con las relaciones de parentesco, las estructuras familiares y sociales que determinan las penas, las sanciones y las normas se vuelven incomprensibles y, por consiguiente, el quehacer en la defensa o persecución de delitos se dificulta en el mejor de los casos y, en el peor, causa 
conflictos en las comunidades y entre quienes acceden a la justicia, porque se manejan lógicas jurídicas, referentes o parámetros culturales diferentes. ${ }^{3}$

Para comprender esto es menester hacer referencia a lo que se enseña en las escuelas de derecho acerca de lo que es la norma jurídica y las características sobre las cuales no siempre se encuadra la norma jurídica indígena, o simplemente, la norma indígena. Por ello, para Correas (2011), el derecho indígena es tan válido o más que el derecho mexicano, y establece criterios de validez que pueden utilizarse para justificar al primero frente al segundo. Así se comparte este planteamiento, ya que sostiene que la validez de las normas jurídicas está en su eficiencia y su eficacia. Sin embargo, se toma distancia de su postura porque el desarrollo de su argumento no considera en su complejidad a las sociedades indígenas, es decir, las considera separadas de la sociedad y el Estado mexicanos, de sus influencias económicas, políticas y culturales, rayando en la idealización de ellas, hasta el punto de plantear que no hay clases sociales en su composición. Si bien el propósito es analizar el derecho indígena desde sus propios parámetros, se está consciente de que una postura idealizada sobre los sistemas jurídicos indígenas, como armónicos, sin errores ni problemas de aplicación, corre el riesgo de no considerar los juegos de poder que también existen en las sociedades indígenas.

Rabasa (2002) es otro jurista importante que ha mostrado cómo se concibe el derecho indígena desde el derecho positivo mexicano. Así, para referirse al derecho indígena hace un recuento de la historia de México y de cómo lo indígena y los derechos de indígenas y de sus pueblos se incorporan a la discusión de reforma constitucional. Su trabajo es valioso porque contextualiza las luchas contemporáneas sobre los derechos indígenas, pero también debe señalarse una distancia sobre su planteamiento, ya que no considera al derecho indígena en sus propios términos, y requiere de la teoría constitucional mexicana de corte estatista y positivista para explicar los derechos indígenas; uno de estos es justamente el derecho a tener su propio derecho.

Por su parte, Durand (2002) hace un reconocimiento al derecho indígena en toda su integridad. Sin embargo, y aunque intenta referir por ejemplo el derecho maya en su historia y cosmovisión, no puede evitar caer en la catalogación de normas e "inventario" [sic] de usos y costumbres de "tradición maya" [sic] a la manera del derecho positivo.

Justamente el autor no aborda cómo esos valores e instituciones indígenas son parte consustancial de la cosmovisión y cultura indígena y a la vez tienen influencias españolas y del Estado mexicano; tampoco explica cómo están involucrados en el sistema de normas y de "hacer justicia" entre los pueblos mayas, y sucede lo mismo en el tratamiento que da del derecho triqui. Esos valores que se construyen histórica, social, territorial y culturalmente son los que distinguen al derecho mexicano del derecho indígena, por lo que se toma en cuenta el trabajo de este autor; sin embargo, también se marca distancia, porque su método de análisis le impide establecer distinciones fundamentales entre el derecho mexicano y el derecho indígena, algo considerado crucial para nuestro análisis.

\footnotetext{
${ }^{3}$ Como lo apunta Oscar Correas (2011) sobre la utilidad de la Teoría General del Derecho (TGD) para comprender al derecho indígena: “También la dificultad para reconocer al sistema normativo indígena como 'derecho' proviene de ideologías, como la de 'soberanía', que no tienen plausibilidad teórica y que deben ser dejadas de lado por la ciencia social contemporánea. La eficacia del sistema jurídico dominante proviene, entre otras cosas, precisamente de la ideología en que son educados los juristas. Si las normas válidas son las que tienen efectividad y pertenecen a un sistema eficaz, como quiere la TGD, entonces como las normas del derecho indígena son las eficaces, son también las válidas. Sin embargo, esta validez es desconocida por los funcionarios del sistema hegemónico, que no han sido educados para pensar en la posibilidad del pluralismo jurídico" (Correas, 2011, p. 89).
} 
La pluralidad de sistemas jurídicos existe de facto como fenómeno social e histórico, y en espacios reducidos donde existe el control comunitario, lo jurídicamente propio (que puede ser lo ajeno reapropiado y resignificado) se impone a lo jurídicamente externo - las decisiones de un juez o un decreto presidencial- . Pero el sistema jurídico hegemónico siempre se impone, y los derechos reconocidos se tornan insuficientes para que los indígenas y sus pueblos apliquen sus sistemas normativos propios, o resulta muy complicado que estos se manifiesten y desplieguen de la misma manera que el derecho mexicano.

En consecuencia, la relación entre sistemas o interlegalidad no se da en igualdad de condiciones, pues prevalece uno sobre otro. En este sentido, podemos ubicar tres formas de relación entre sistemas legales: la primera, entre sistemas jurídicos que coexisten en un territorio, ambos se aplican, pero que son independientes entre sí; un ejemplo podemos encontrarlo en los primeros trabajos realizados en Oaxaca por Carmen Cordero Avendaño de Durand (2009), en los que la autora trató de mostrar que en las sociedades indígenas también había normas a la manera del derecho mexicano. Sin embargo, al no tomar la autora en cuenta los contactos culturales entre sociedades, su análisis se inclinó a mirar con cierto romanticismo los sistemas jurídicos indígenas, y quedaron sin considerar ni mostrar suficientemente los juegos de poder en las comunidades indígenas, y más aún frente al Estado. Indudablemente su trabajo es valioso y valdría la pena continuarlo desde un enfoque de mayor complejidad, tratando de distinguir los ámbitos propios del derecho indígena, distintos de los del derecho mexicano, y estudiarlos en su interrelación.

Existe un segundo tipo de vinculación entre los sistemas jurídicos coexistentes y es una mutua constitución de legalidades, que sería la reapropiación de esa influencia del derecho positivo por parte de los indígenas, quienes al invocar las normas estatales las hacen suyas dándoles otro sentido (como la figura del municipio y la agencia municipal, el comisariado agrario y otras); y el tercer tipo de relación consiste en sistemas jurídicos coexistentes y con miradas distintas sobre un mismo objeto (Sánchez, 1998) que deben tomarse en cuenta para justamente lograr una justicia intercultural. En esta, el juez del estado conoce la costumbre de la persona indígena sujeta a un proceso, el defensor también y se cuenta con un intérprete traductor, para poder dar cuenta de las diversas miradas sobre una misma conducta o hecho: la brujería como conducta inapropiada que puede provocar un daño, las estructuras de organización indígena que propician la resolución o previenen un conflicto (los curanderos que son considerados abogados en algunas culturas indígenas de México y que interceden frente a las divinidades y los brujos); precisamente aquí es donde se ubica la propuesta de este artículo.

En ese sentido, González (1997), en su trabajo, compara las bases de los sistemas normativos indígenas entre sí para dar cuenta de sus características generales. De tal suerte, el autor intenta dilucidar el pensamiento indígena que se entrecruza en sus sistemas normativos, exponiendo a grandes rasgos elementos comunes entre sistemas indígenas a partir de estudios antropológicos sobre varios sistemas: tacuate, tojolabal y huichol. Se considera por ello que su investigación es un antecedente importante del presente trabajo.

Una propuesta frente a la de González (1997) supone dar un paso adelante, y visibilizar los ámbitos de la justicia indígena y de sus normas más allá de lo material y lo evidente, considerando otros planos de entendimiento que denominamos ámbitos: el espiritual y el del mundo superior, en los que más adelante se abundará. 


\title{
El punto de transición entre lo ajeno y lo propio: la antropología y la antropología jurídica
}

Para dilucidar el quehacer de la antropología y de la antropología jurídica y su papel para dar cuenta de los sistemas jurídicos indígenas y la pluralidad de centros generadores de normas jurídicas y derecho, es importante remitir al interés central de estas disciplinas, que es fundamentalmente el conocimiento del "otro" ser humano distinto y diferente a mí, y a la vez semejante; por su existencia constato mi singularidad y a la vez la diversidad de la sociedad humana. En palabras de Esteban Krotz:

\begin{abstract}
Abundando un poco, este problema de identidad y diferencia humana también podría expresarse así: es la pregunta por los aspectos singulares y por la totalidad de los fenómenos humanos afectados por esta relación, que implica tanto la alteridad experimentada como lo propio que le es familiar a uno; es la pregunta por condiciones de posibilidad y límites, por causas y significado de esta alteridad, por sus formas y sus transformaciones, lo que implica a su vez la pregunta por su futuro y su sentido (Krotz, 1999, p. 16).
\end{abstract}

De esta manera, la antropología mexicana surge justamente de esa experiencia de otredad dada por la sorpresa frente a lo exótico, que es ajeno, pero a la vez es propio porque se reconoce como parte de la historia mexicana - por ejemplo, los vestigios arqueológicos, que forman parte del pasado, pero sin ellos no se podría explicar el presente-:

Al insertarse en esos contextos, el antropólogo como sujeto se "extraña". Frente a lo "exótico" del objeto, el sujeto que conoce tiene como primera "sensación" la "extrañeza", que puede incluir tanto la sorpresa, la rareza e incluso la admiración. La extrañeza proviene de la distancia social —física e intelectualque separa al antropólogo de su objeto (Boivin, Rosato y Arribas, 1999, p. 154).

Y, de igual forma, con esa extrañeza se puede comprender lo propio, de acuerdo con Mauricio Boivin, Ana Rosato y Victoria Arribas, haciendo referencia al trabajo de Da Matta,

quien sostiene que la transformación de lo familiar en exótico significa un punto de partida, ya que la única forma de estudiar al "nosotros" es tomarlo como exótico. Eso implica una desvinculación emocional, no necesariamente cognitiva, con nuestra propia cotidianidad. Por el contrario, cuando transformamos en familiar lo exótico, esta transformación es un punto de llegada (Boivin, Rosato y Arribas, 1999, p. 154).

De esta manera, la antropología mexicana transita en esos ejercicios analíticos de la realidad y del conocimiento, entre lo propio y lo ajeno. La antropología jurídica, como disciplina derivada de la antropología social, no es ajena a esos procesos de conocimiento de lo diverso.

La mirada antropológica es una aportación crucial a los estudios del derecho en contextos multiculturales, porque no basta con observar la norma por sí misma o fijarnos en el desarrollo de lo jurídico en ámbitos sociales concretos ni en los usos del poder para generar normas y aplicarlas —sociología 
jurídica-; es menester agregar el elemento cultural, como visiones diversas del mundo que se concretan en las lenguas indígenas, en las formas de gobierno y organización, para comprender la relación de los Estados nacionales con los indígenas y sus pueblos, para garantizar el ejercicio de derechos en sociedades reconocidas como pluriculturales (léase art. $2^{\circ}$ de la CPEUM). Para esto, para el análisis de lo jurídico y para garantizar el acceso a la justicia y que esta sea verdaderamente intercultural, y en su caso el pluralismo jurídico sea cabal en su expresión normativa, la visión antropológica no solo es fundamental, sino que también es necesaria.

La antropología mexicana, con raíces plenamente definidas en la historia de la Revolución mexicana y en los orígenes del Estado revolucionario, es esencial en la búsqueda de las bases de la identidad de la nación mexicana, y surge en México sobre las bases del desarrollo de la arqueología, de acuerdo con Matos (2001), quien recuerda a Manuel Gamio:

En 1917 se creó el Departamento de Arqueología y Etnografía como parte de la Secretaría de Agricultura y Fomento, siendo secretario de la misma Pastor Rouix. Gamio fue nombrado al frente del departamento, que en 1919 cambió su estatus, pasando a convertirse en Dirección de Antropología. Ya para entonces, Gamio había escrito acerca de su concepción de la arqueología, plasmando los comienzos de su idea de la antropología como ciencia que estudia al hombre.

Así, en 1914 escribía lo siguiente en Metodología sobre investigación, exploración y conservación de monumentos arqueológicos, obra publicada por el Museo Nacional: "Las investigaciones tendrán un carácter integral, pues comprenderán el estudio de las manifestaciones culturales, tanto las intelectuales (mitología, ideas estéticas, etc.) como las materiales (construcciones, cerámica, implementos diversos, etc.); el de los restos humanos, el de restos animales y el del ambiente físico biológico local" (Gamio, 1914).

Poco después, en 1916, la Editorial Porrúa publicó el libro Forjando Patria, que contiene diversos artículos de Gamio entre los que destacamos el que titula "Concepto sintético de la arqueología”, en donde ya está presente su visión antropológica [...].

La antropología suministra el conocimiento de los hombres, y de los pueblos, de tres maneras: 1) por el tipo físico, 2) por el idioma y 3) por su cultura o civilización” (Gamio, 1916) (Matos, 2001, p. 38).

De esta manera, existe un consenso de que la antropología mexicana sienta sus orígenes en una:

relación orgánica con el Estado mexicano tanto por su acompañamiento en la construcción de una identidad nacional, como por el liderazgo en la política indigenista. Lo cual hace comprensible que su distanciamiento con el Estado, al final de la década de 1960, sirvió de disparador de una gran diversidad de espacios de acción y temas a investigar (Bueno, 2010).

En tal sentido, la antropología jurídica mexicana se erige sobre esas bases y se distancia del Estado mexicano, centrando sus intereses en las formas y procesos sociales y culturales por los cuales se producen y aplican las normas jurídicas. Así, se podría decir que, más que por la norma jurídica en sí misma, se interesa por el estudio de las interacciones entre normas y prácticas sociales y culturales, entre el deber ser y el ser, sobre todo en aquellos ámbitos en los que están en tensión y no tanto en correspondencia, 
no tanto en su imbricación sino en su inconmensurabilidad. Para lograrlo, es importante la colaboración interdisciplinaria en el estudio de las normas y las prácticas sociales.

Así, Chenaut y Sierra (1995) plantean que el estudio de la interrelación entre normas y prácticas sociales solo puede ser posible desde la interdisciplina. Mientras el derecho otorga las herramientas para acercarnos al universo normativo, la antropología social permite reconocer y descifrar el entramado de redes sociales propio de las prácticas, y discutir, asimismo, el contenido cultural de las normas. De esta manera, una visión antropológica del derecho entiende lo jurídico no solo en el acto de normar o de establecer límites, sanciones y controles, sino que involucra también el análisis de las relaciones de poder y de las jerarquías en las comunidades indígenas, y de otras, que lo hacen vigente y eficiente, y sobre todo toma en cuenta el análisis de la relación entre el Estado y la sociedad con los pueblos indígenas.

Por ello, en los orígenes de la antropología jurídica mexicana, y por la necesidad de establecer diálogos interdisciplinarios entre la antropología y el derecho, la primera cedió a las categorías de este para entender la norma jurídica indígena, y esta postura se siguió en la aplicación de las categorías de interlegalidad e hibridación (combinación de las normas indígenas y estatales para dar lugar a algo distinto a ambos), que privilegian los criterios de valor y conceptos del derecho positivo mexicano para calificar si un sistema normativo es o no derecho. Si bien tanto las categorías jurídicas como las antropológicas han sido útiles para establecer puentes de entendimiento y hasta cierto punto de reconocimiento de derechos de indígenas y sus pueblos, se considera que ha quedado relegada una parte importante del reconocimiento de la diversidad cultural, expresada en las formas y maneras en que los pueblos indígenas se ubican en el mundo y lo entienden y, por consiguiente, la comprensión de cómo este sentido de mundo se expresa en lo que se llama derecho indígena.

Al hacer una revisión de la literatura que se refiere justamente a la relación del derecho positivo con el derecho indígena —-se entendió este como expresión del pluralismo jurídico—, la interlegalidad y los usos de poder, se aprecia que: 1) los estudios toman como eje central de referencia al derecho positivo y desde ese lugar observan el "comportamiento" del derecho indígena; 2) los estudios que intentan tomar como eje central el derecho indígena fracasan porque siempre lo hacen en su relación y comparación con los elementos del derecho mexicano, por lo que se muestra no tanto el derecho indígena como algo propio, sino que resaltan las influencias y efectos del derecho positivo en el derecho indígena/nativo/ originario y muy poco, por poner un ejemplo, las influencias de este sobre aquel; 3) dada la reivindicación indígena y de sus pueblos por más de veinte años, se observa que son prácticamente inexistentes los estudios que tienen por objeto el derecho indígena como eje central de análisis y que no toman en cuenta como referencia central el derecho positivo. Por ejemplo, en el derecho odam los curanderos funcionan como abogados, y su contrafuerza, la brujería, aparece en la dimensión de los sueños para resolver conflictos, mostrándose esto en la dimensión de la realidad material.

\section{Principios generales del derecho indígena}

Una manera de dar un paso más hacia delante y tomar distancia de una concepción estatista y positivista del derecho, para apreciar el derecho indígena como producto social y cultural, fue justamente plantear los principios generales del derecho indígena, trabajo publicado en años pasados por Cruz (2008).

Se reconocen las influencias y transformaciones que los sistemas jurídicos indígenas experimentan dada la incorporación de referentes culturales externos. Pese a esto, se postula que el derecho indígena 
mantiene principios generales que le dan especificidad como sistema jurídico y son su base. En el caso de Oaxaca, diversos ideólogos indígenas hablan de comunalidad; más adelante se hablará de este término.

En este trabajo se asume el enfoque del pluralismo jurídico - como interacción y mutua constitución de legalidades-, así como el enfoque antropológico de la otredad y la alteridad, todo en la búsqueda de reconstruir miradas distintas sobre un mismo objeto, como puede ser la conducta humana en espacios de contacto cultural y de interculturalidad.

De esta manera, se plantea que, para entender el derecho indígena, más que hablar de normas, se debe hablar de principios generales del derecho indígena como criterios que la conducta humana debe seguir en cierta situación. Estos principios emanan, por un lado, del devenir histórico de una comunidad indígena en su relación con cada una de las comunidades vecinas que conforman el grupo etnolingüístico colindante y coexistente en un territorio - por ejemplo, un municipio o una región-y, por otro, de la relación de estas unidades - comunidades, agencias, cabeceras, municipios, regiones- con el pueblo indígena o grupo etnolingüístico del que forma parte. El principio fundante en el que descansa este cuerpo de principios étnicos y axiológicos en muchos de los casos es el de bien común, comunalidad o comunalismo (Cruz, 2008, p. 35), que en el dinamismo social tiene su fuente primaria en las relaciones de parentesco y de familia, es decir, se habla de bien común de la familia, del barrio, del paraje y de todos.

El principio elemental del sentido de comunidad o comunalidad es consustancial del derecho indígena; esto implica un estudio sincrónico y diacrónico exhaustivo de la comunidad y pueblo indígena del cual se quiera dar cuenta de su derecho indígena, aunque, por su complejidad, no se ha podido encontrar estudio alguno sobre esta materia concreta.

Pese a esta circunstancia, es necesario empezar a partir de algo, por lo que tomaremos como punto de partida el análisis reflexivo que pensadores indígenas y no indígenas han realizado.

\section{El derecho indígena desde sus propios parámetros}

Como se ha expuesto, hacer un comparativo del derecho indígena desde sus propios parámetros —más allá de la mirada estatal normativista y de lo constatable por los sentidos- es pertinente dado que los estudios sobre este tema lo hacen tomando como referencia central el derecho positivo y desde ese lugar se observa el "comportamiento" del derecho indígena; también intentan hacerlo desde las dinámicas sociales propias, pero siempre en comparación con el derecho positivo. Por otro lado, los estudios que intentan tomar como eje central el derecho indígena lo hacen comparándolo con los elementos del derecho mexicano; muestran el derecho indígena con influencias y efectos del derecho positivo, y no como algo con una estructura propia. Por ello, de lo indagado hasta ahora se puede decir que los estudios que tienen como eje central de análisis el derecho indígena y que no toman como referencia el derecho positivo son prácticamente inexistentes.

\section{Los parámetros del pensamiento indígena y sus campos}

Se entiende por parámetro el "cuenco" o medida construido dentro del sistema de pensamiento indígena que explica lo que se considera que es normativo o la norma que rige la conducta humana. Es decir, existen diferentes planos y dimensiones; así, el parámetro o medida dependerá de cada uno de ellos y de la cosa, objeto o pensamiento que cada comunidad y pueblo etnolingüístico considere que forma parte de cada dimensión o plano: material, espiritual o del mundo superior. 
Una consideración para tomarse en cuenta, y que puede estar ubicada en el plano material, es la que tiene que ver con las formas de organización indígena que resultan de la conformación histórica, social y cultural de las comunidades indígenas como parte de pueblos etnolingüísticos mayores, con lógicas de relación familiar y comunitaria diferentes a las sociedades no indígenas, o a las sociedades nacionales y por tanto más afines a la estructura del Estado y a sus orígenes. Otra consideración que debe tomarse en cuenta en esta definición de parámetros, y que se ha constatado en el trabajo con comunidades indígenas, es el conocimiento tradicional, que se ubica en el plano de lo espiritual y en el del mundo superior, ya que en muchos casos se le considera como "dones" o atributos que recibe el ser humano - hombre o mujer, niño o niña - por una deidad o epifanía. En otras palabras, como lo señalan sobre todo intelectuales indígenas (López, 2018), la concepción y el pensamiento que las sociedades indígenas tienen sobre la conducta humana no la disocian o parcelan por campos — religioso, jurídico, espiritual y familiar-; por lo tanto, el ser y el deber ser no están separados.

En cambio, el pensamiento jurídico mexicano es estatista y parcelado; es el Estado el que califica si una norma es norma de derecho (civil, familiar, ambiental, mercantil o penal), es decir, norma jurídica, si es válida o no, y separa el ser del deber ser, aquel son las conductas y este son las normas.

Una tercera consideración se refiere a los procesos de transmisión del conocimiento - la tradición oral- y a la especialización. Así, en las sociedades indígenas existen personas expertas en distintos campos: uso de plantas comestibles y medicinales, elaboración de textiles y prendas, desarrollo del pensamiento matemático, agricultura, historia, tradición oral, práctica del rezo, diagnóstico de enfermedades por el pulso o por lectura del maíz; chamanismo, curanderismo, uso de espacios sagrados y el hacer justicia. En estas prácticas/conocimientos pueden coexistir y conjugarse los tres planos, por eso son círculos que tienen puntos centrales de cruce. Las actividades desarrolladas en estos campos de especialización por lo regular son altamente apreciadas por los pobladores indígenas de la comunidad, y pueden ser remuneradas de distintas formas, ya sea con dinero o en especie. De esta manera, en el hacer justicia se pueden poner en juego normas de las dimensiones espiritual, material y del mundo superior.

Como se ha señalado, para comprender esto se requiere conocimiento de la historia y del devenir de la comunidad en su relación con el pueblo etnolingüístico al que pertenece y de los sentidos de mundo, es decir, cómo explican su lugar en el mundo material y su relación con cada una de las dimensiones y planos: los dueños de los lugares como son el manantial, el volcán, la cueva. Una ventana a ese sentido de mundo es la lengua - como cuarta consideración para definir parámetros- que, como tal, es a la vez epicentro y punto de intersección de los diferentes planos/dimensiones.

\section{La lengua}

Las lenguas indígenas, así como las extranjeras, son parte importante de cada cultura, pues en ellas están presentes su origen e historia. La lengua implica algo más que únicamente comunicar; trata de manifestar ideas profundas, expresiones que derivan de la sabiduría ancestral, de los aprendizajes obtenidos e incluso forjan la identidad cultural de cada persona.

Fidencio Briceño Chel (2018) plantea que las lenguas son un rasgo característico de cada pueblo, y hace un análisis de la lengua maya a partir de su gramática y de cómo esto influye y se refleja en la cultura e identidad de quienes, como él, se consideran mayas peninsulares. Su trabajo resulta valioso porque explica la función de la lengua en la vida y el pensamiento mayas. 
De igual forma plantea que no debe restringirse el plano lingüístico a lo meramente verbal, ya que existen otros códigos que son importantes para llevar a cabo la comunicación.

Por lo anterior, cuando Briceño se refiere al "nosotros" lo hace desde las categorías gramaticales. Mediante esa categorización pretende demostrar cómo se incluyen o excluyen los grupos, es decir, cómo el nosotros se diferencia de los otros, cómo el "nosotros" puede ser inclusivo, si se trata de una pluralidad que unifica a los diferentes "yo-s" e incluye al "tú", o excluyente si en este se incluye a los otros sin tomar en cuenta al "tú". Lo anterior es una cuestión de pertenencia y exclusión, de cómo funcionan los colectivos en cuanto a la identificación de la existencia de identidades diferentes; en definitiva, para entablar la comunicación entre hablante y oyente.

De esta manera, en el discurso maya, el autor advierte cómo los distintos "nosotros" pueden implicar una polisemia maya, es decir, el solo término "nosotros" en lengua maya tiene una diversidad de significados y, dependiendo del sentido y contexto que se les dé, puede tener diferentes connotaciones. Esto se debe a la forma que tienen los mayas de ver la vida puesto que el panorama es abierto y, por eso, lo que sucede gradualmente otorga un significado distinto, más profundo y reflexivo a las palabras.

El autor se adentra en la complejidad polisémica de la lengua maya planteando la dualidad de conceptos, es decir, "el mundo bipartito". Si se entiende que las palabras mayas no pretenden ser literales, y que los significados pueden variar, la bipartición de estos términos es un juego de antítesis, es decir, una misma palabra puede significar dos cosas opuestas. Sin embargo, lo interesante de las oposiciones es que explican toda una cosmovisión, cómo el uno complementa al otro desde su contrariedad y este cierra un ciclo que continúa, tal como sucede en la propia vida. Esto, visto gráficamente, son los llamados planos y dimensiones.

\section{La persona en los sistemas legales}

El punto central de lo que interesa al derecho positivo mexicano, y que es centro de regulación, es el concepto de persona - lo que es "la persona maya" para Briceño (2018)—. Se plantea que la identidad de la persona se crea a partir del lenguaje y de sus experiencias en su vivir cotidiano, es decir, aparentemente no hay "deber ser" — precepto normativo - de lo que tendría que ser la persona. Sin embargo, cuando el autor señala que la cultura maya se basa en la creencia de los ciclos que se abren y cierran para crear otros, la persona que está por iniciar la forja de su identidad debe aprender a comprenderse y explicarse en el mundo, para completarse en un círculo y así poder abrir otros. Esto es lo normativo, pero no a la manera del derecho positivo mexicano, que es lineal y no comprende otro mundo más que el ámbito/espacio material.

El concepto de persona como centro de regulación del derecho, y por tanto como punto de tensión y debate entre el derecho positivo mexicano y el derecho indígena, es más claro si tomamos en cuenta que cada pueblo tiene un concepto de "persona" que depende del sentido de mundo que sustenta su existencia en el mundo material y en los distintos planos y dimensiones. También depende de las responsabilidades que asume el individuo, pero también de los ritos de transición por los que debe pasar, y en los que pasa de ser solo un "ser vivo", a ser un "ser con conciencia" de sus responsabilidades individuales, sociales y espirituales. Por su parte, el derecho positivo postula que la persona es aquella que es concebida y no nacida; como tal tiene derecho, aun cuando no haya nacido, a recibir herencia. Esto para los pueblos indígenas no es posible; por ejemplo, en Chiapas, entre los tsotsiles se dice que la 
persona no "es" hasta que su chu'lel no está maduro; es decir, un niño pequeño es un ser vivo, pero no es todavía persona, circunstancia que provoca tensión con el derecho positivo. Pese a estas diferencias, los aspectos concernientes a lo que se debe considerar que es la persona como centro de regulación de la norma no se debaten ni se abordan. Lo mismo ocurre con el tema de la brujería, que se coloca como aspecto de tensión entre el positivismo jurídico y el pensamiento indígena. Así, parece que existiera un acuerdo tácito, entre antropólogos y juristas - y en cierta manera también asumida por los indígenas y sus pueblos-, de dejar cuestiones como estas a un lado, para seguir hablando o abonando sobre lo que sí se puede observar como imbricado o se puede acordar, y que puede tener cosas en común para los dos pensamientos, es decir, lo que está únicamente en el plano/dimensión material, como puede ser la normatividad de la conducta y de los derechos (véase artículo 2 de la CPEUM).

\section{Respeto en todas las dimensiones y planos}

Para continuar con la explicación del pensamiento maya, Briceño (2018), se refiere a "la metáfora en la vida maya”. Tanto en el discurso como en la práctica, para los pueblos indígenas el uso de la metáfora siempre ha sido primordial para generar sabiduría y comprender el mundo puesto que, desde su visión, todo lo que les rodea, aparte de los seres humanos, tiene vida, por lo que las metáforas son piezas invaluables en su concepción. En este sentido, el respeto no se limita únicamente al establecido entre humanos, pues implica al ser humano en su relación con el entorno; todo es sagrado, incluso las piedras, pues tienen su razón de ser y estar en el mundo, como entes que son y como parte de él.

Partiendo de la premisa de cómo se construye la identidad de la persona maya y cómo se distingue desde su inclusión y exclusión con "los nosotros", se puede hablar de la construcción social del maya, es decir, del vínculo del maya con su entorno y esa construcción social que tiene que ver con la relación de la persona con los humanos, los seres vivos no humanos, e incluso los seres espirituales, puesto que también son parte de su cultura.

Finalmente, para el autor, la identidad de la persona está conformada por su integración a la sociedad y por la manera de participar en ella. Así, en ambos casos pone en juego o manifiesta su concepción sobre el mundo, que tiene íntima relación con el aprendizaje sobre las diferentes formas de interacción tanto con los otros humanos, como con los que no son humanos. De cualquier forma, ambos convergen en un punto de respeto recíproco.

\section{Tradición oral y especialización}

Un ejemplo que muestra lo expuesto por Briceño (2018) es el trabajo de María Jesús Cen Montuy (2017) sobre la normatividad de los nunkinienses.

La autora muestra las formas de organización indígena, y sobre todo de hacer justicia, y cómo en estas se observan esos usos del lenguaje y, por tanto, del pensamiento indígena sobre lo que es o debe ser la persona como ente en el que se conjuntan de manera coherente y equilibrada los planos/dimensiones.

Ella enfoca la mirada en lo que señala como elementos centrales de la normatividad conciliatoria maya nunkiniense, y reconoce lo que denomina planos/dimensiones del pensamiento indígena que se expresan en la regulación de la conducta a través de tres principios: todo tiene su dueño, hay que ser agradecidos y respetuosos, y hay que respetar, cumplir la palabra — ser responsables- y ayudarse. 
De esta manera, la autora reconoce la normatividad del mundo superior - las deidades representadas en los santos: santo patrono, caballero de fuego—, la normatividad ritual y festiva, la normatividad espiritual y la normatividad conciliatoria.

Sobre la normatividad conciliatoria, la autora explica cómo en el pensamiento de uno de los jueces indígenas que entrevista — reconocido por el derecho positivo mexicano o la ley estatal — se entrecruzan el castigo divino del santo patrono del pueblo y la acción humana de hacer justicia. Así lo comenta Cen (2017), al recoger en su escrito esta entrevista:

Explicó que los nunkinienses siempre han sido muy católicos y creyentes de San Diego de Alcalá y que eso, en parte le ayudaba en su trabajo porque la gente temía que el santo los castigara, pues todos en el pueblo sabían "que San Diego tiene su poder".

Somos muy creyentes del santo san Dieguito, entonces lo pensaban; así que hay que portarse bien para que el santo no se moleste. Yo lo creo que sí tienen razón, muchos decían así que si te portabas mal, el santo te castigaba, que si lo prometías al santo algo pues lo tenías que cumplir, ¡mare! Te castiga si no lo cumples. Todavía creemos en el santo (don José, Nunkini, entrevista de 2012, en Cen, 2017, p. 194).

También la autora muestra cómo el pensamiento acerca de la persona, como parte del mundo material en su relación con el mundo espiritual y superior, se expresa en la concepción y creencia sobre los dueños de los lugares: el monte, los manantiales, la tierra y el bosque (Cen, 2017).

Lo expuesto por la autora sobre el ejercicio especializado del conocimiento indígena es más claro cuando más adelante se refiere al ejemplo de un juez indígena que además era jmeen y que, por esa cualidad o don, sí podía resolver lo que otros jueces indígenas no podían.

\section{Planos y dimensiones: lo superior, lo material y lo espiritual}

Como se observa, tanto en la exposición de Briceño (2018) como en la de Cen (2017) se muestra la constante de la existencia de los planos/dimensiones que se postulan como presentes de manera integral en el pensamiento indígena y que rigen la conducta humana.

Ahora, brevemente se hará referencia al caso de un estudioso integrante del pueblo tepehuano o autollamado odam de Durango, México. Honorio Mendía, en su trabajo La justicia oral y comunal: el caso de los tepehuanos del Sur (Santa María de Ocotán y Xoconoxtle, Durango) (2016), hace alusión a esas dimensiones y en una entrevista explicó el siguiente suceso, ejemplo de lo que se quiere demostrar y seguir estudiando.

Contó Mendía que, en su pueblo, mediante los sueños, se resolvían conflictos que definían relaciones sociales concretas. Y esto es por el ejercicio especializado de los llamados curanderos o chamanes.

Honorio Mendía es un iniciado del chamanismo porque en algún momento de su vida un chamán detectó que él también tenía el don de ser curandero. Por eso para los pasos que da debe pedir permiso con la autoridad, pues su obligación es permanecer en la comunidad para formarse en esa especialidad. Y aunque él ha preferido salir, para estudiar, debe llegar periódicamente para honrar a los ancestros y cumplir con una serie de rituales. En una de esas ocasiones en las que llegó a su comunidad pidió a la asamblea que le permitiera hacer su tesis de maestría en antropología jurídica y la asamblea aceptó. Una noche soñó que se encontraba en el camino a la bruja del pueblo, quien le arrebató la libreta y le 
aseguró: "No vas a acabar la tesis". Él despertó muy alterado y al día siguiente fue a ver al curandero del pueblo. Este le dijo: “¡Ah, mira, ella es muy fuerte!, permíteme, voy a soñar y ven mañana”. Al día siguiente volvió Honorio y el curandero le dijo que la bruja era realmente fuerte, que no se dejaba, pero le insistió: "Dame otro día y, si no puedo, buscas a otro". En la segunda ocasión que llegó Honorio con el curandero, finalmente le dijo que lo pudo hacer, que pudo intervenir, que recuperó su libreta y le comunicó que sí iba a poder terminar la tesis; también le dijo que precisamente, en el sueño, había logrado que las autoridades hablaran con la bruja.

Esto muestra la existencia de un plano que no es el material; en el pensamiento indígena fue efectivo para resolver una disputa. Así, se puede ver cómo, en este ejemplo, en el sueño se conjuntan las dimensiones de lo material, lo espiritual y el mundo superior.

\section{Reflexiones finales}

El pluralismo jurídico, como la existencia de campos jurídicos que pueden estar en relación estrecha —imbricación-o en coexistencia con ciertos préstamos y adaptaciones — hibridación-, es una realidad fáctica cuyo reconocimiento jurídico dista mucho de ser concretado debido a que, como hemos expuesto, los estudiosos, tanto desde la antropología jurídica como desde el derecho, no han podido dar cuenta del derecho indígena sin referirse al derecho estatal o al derecho mexicano, cuya esencia es hegemónica: no hay otro derecho, solo el que produce el Estado mexicano.

Es difícil pensar en el derecho sin referirnos al Estado nacional, y parece una paradoja hablar del derecho indígena sin que sea reconocido por el Estado, o más aún, resulta difícil el reconocimiento del pluralismo jurídico con bases pluriculturales sin establecer mecanismos de transmisión de facultades amplias y recursos económicos a los indígenas y sus pueblos, concretizando su ejercicio. Esto sería finalmente un verdadero reconocimiento del pluralismo jurídico.

Hablar del derecho indígena es justamente hablar de un proceso histórico de México, que no ha resultado fácil para nadie y que ha sido encabezado justamente por los indígenas y sus pueblos. Sin embargo, no solo ellos son los involucrados; es decir, cuando se habla de pluriculturalidad, se piensa inmediatamente en los indígenas, pero ellos no son la única representación de esa pluriculturalidad, ni de esa diversidad, pues esta abarca también el género, la edad además y la adscripción étnico cultural. Por ejemplo, los afrodescendientes o grupos de menonitas con presencia en varios estados de la República mexicana, así como las personas provenientes del extranjero, como estadounidenses, italianos, etcétera; las mujeres, los niños y los jóvenes, ellos y ellas también representan la diversidad existente en el país.

Hemos planteado que el enfoque de abordaje sobre el derecho indígena debe invertirse. Es decir, más que comparar el derecho indígena con el derecho positivo, debemos partir de dar cuenta de los sentidos de mundo que se ponen en juego en el derecho indígena y en el hacer justicia en sus propios contextos y desde sus propios parámetros de pensamiento.

De esta manera, se asume en este artículo la propuesta de Sánchez Botero (1998) cuando subraya la relevancia jurídica diferenciada por los parámetros culturales en los que están asentados tanto el derecho positivo como el derecho indígena. Es decir, cómo estos observan un mismo asunto o evento desde sus propios parámetros, y cómo se pueden entender como “[...] referentes, antecedentes y explicaciones distintas para aproximarse a un fenómeno o a los mundos simbólicos reales no compartidos universalmente, los cuales deben ser valorados por ser ajenos al sistema en que éstos se producen” (Sánchez, 1998, p. 178). 
Es en este punto, después de haber revisado a las autoras que escriben sobre los sistemas normativos desde la antropología, y a los autores que escriben sobre lo mismo desde el derecho, nuestra pretensión de continuar nuestras pesquisas a la luz de la propuesta de Sánchez Botero, es decir, ir más allá del planteamiento inicial de Cruz (2014 y 2018) de la imbricación de una aparente dualidad, y observar el sistema jurídico indígena desde sus propios parámetros para transitar a un verdadero diálogo de saberes que nos permita responder a preguntas tales como: ¿es posible hacer la traducción de los pensamientos y pluriversos de los que no formamos parte?, ¿cómo?, ¿qué hacer para que la traducción cultural no sea parcelada, fragmentada, sí, desde los propios sentidos del mundo al que aspiramos comprender?

\section{Referencias}

Boivin, M., Rosato, A., y Arribas, V. (coords.) (1999). Constructores de Otredad. Una introducción a la Antropología Social y Cultural. https://antroporecursos.files.wordpress.com/2009/03/bolvin-m-rosato-a-arribas-v-2004constructores-de-otredad.pdf

Briceño, F. (2018). Gramática cultural o de cómo la cultura está presente en el pensamiento maya. En F. López (coord.), El pensamiento indígena contemporáneo (pp. 329-342). Suprema Corte de Justicia de la Nación.

Bueno, C. (2010). Logros y vicisitudes de la antropología mexicana a través de su historia. Revista Educación Superior y Sociedad, 15(1), 155-178. https:/www.researchgate.net/publication/289529649_LOGROS_y_ VICISITUDES DE LA ANTROPOLOGIA MEXICANA A TRAVES DE SU HISTORIA

Cen, M. J. (2017). Bo'ol si' ipil, K'eex, Proomesa, Jets't'aan y Su'tsil: una aproximación etnográfica a la normatividad de los nunkinienses [tesis de doctorado, Universidad de Barcelona].

Chenaut, V., y Sierra, M. T. (coords.) (1995). Pueblos indigenas ante el derecho. Centro de Investigaciones y Estudios Superiores en Antropología Social.

Cordero, C. (2009). Supervivencia de un derecho consuetudinario en el valle de Tlacolula (zapotecos). Fonapas; Cámara de Diputados; Miguel Ángel Porrúa.

Correas, O. (2011). La teoría general del derecho frente a la Antropología política. Revista Pueblos y Fronteras Digital, 6(11), 89-115. https://www.redalyc.org/pdf/906/90618647004.pdf

Cruz, E. (2008). Principios generales del derecho indígena. En R. Huber, J. C. Martínez, C. Lachenal, y R. Ariza (coords.), Hacia sistemas jurídicos plurales. Reflexiones y experiencias de coordinación entre el derecho estatal y el derecho indígena (pp. 29-50). Fundación Konrad Adenauer.

Cruz, E. (2014). Derecho indígena: dinámicas jurídicas, construcción del derecho y procesos de disputa. Consejo Nacional para la Cultura y las Artes; Instituto Nacional de Antropología e Historia.

Cruz, E. (2018). Derecho indígena: dinámicas jurídicas, construcción del derecho y procesos de disputa. Consejo Nacional para la Cultura y las Artes; Instituto Nacional de Antropología e Historia.

De Souza, B., y García, M. (2001). El caleidoscopio de las justicias en Colombia. Siglo del Hombre Editores.

Durand, C. H. (2002). Derecho indígena. Porrúa.

González, J. A. (1997). Una filosofía del derecho indígena: desde una historia presente de las mentalidades jurídicas. Boletín Mexicano de Derecho Comparado, 89, 523-538. https://revistas.juridicas.unam.mx/index.php/ derecho-comparado/article/view/3487/4129

Krotz, E. (1999). Alteridad y pregunta antropológica. En M. Boivin, A. Rosato, y V. Arribas (coords.), Constructores de otredad. Una introducción a la Antropología Social y Cultural (pp. 16-21). Antropofagia. https:// antroporecursos.files.wordpress.com/2009/03/bolvin-m-rosato-a-arribas-v-2004-constructores-deotredad.pdf

Krotz, E. (2002). Sociedades, conflictos, cultura y derecho desde una perspectiva antropológica. En E. Krotz (ed.), Antropologíajurídica: perspectivas socioculturales en el estudio del derecho (pp. 13-49). Anthropos; Universidad Autónoma Metropolitana.

López, F. (coord.) (2018). El pensamiento indígena contemporáneo. Suprema Corte de Justicia de la Nación.

Matos, E. (2001). La antropología en México. Revista Ciencia, octubre, 36-43. https://www.revistaciencia.amc. edu.mx/images/revista/51_3/antropologia.mexico.pdf

Mendía, H. (2016). La justicia oral y comunal: el caso de los tepehuanos del Sur (Santa María de Ocotán y Xoconoxtle, Durango) [tesis de maestría, Facultad de Filosofía, Universidad Autónoma de Querétaro].

Rabasa, E. (2002). Derecho constitucional indígena. Porrúa; Universidad Nacional Autónoma de México. 
Sánchez, E. (1998). Construcciones epistemológicas para el conocimiento de los sistemas de derechos propio y de las justicias indígenas: el caso colombiano. América Indígena, LVIII(1-2), 177-199.

Sierra, M. T. (1996). Antropología jurídica y derechos indígenas: problemas y perspectivas. Dimensión Antropológica, 8, 55-90. http://www.dimensionantropologica.inah.gob.mx/?p=1439

Sierra, M. T., y V. Chenaut (2002). Los debates recientes y actuales en la antropología jurídica: las corrientes anglosajonas. En E. Krotz (ed.), Antropología jurídica: perspectivas socioculturales en el estudio del derecho (pp. 113180). Anthropos; Universidad Autónoma Metropolitana.

Stavenhagen, R., e Iturralde, D. (comps.) (1990). Entre la ley y la costumbre: el derecho consuetudinario indígena en América Latina. Instituto Indigenista Interamericano; Instituto Interamericano de Derechos Humanos. 